\title{
KLASIFIKASI HABITAT MANGROVE UNTUK PENGEMBANGAN SILVOFISHERY KEPITING SOKA (Scylla serrata) DI PANTAI UTARA KABUPATEN REMBANG
}

\section{ERNY POEDJIRAHAJOE}

\author{
Bagian Konservasi Sumberdaya Hutan, Fakultas Kehutanan, Universitas Gadjah Mada \\ Jl. Agro No.1, Bulaksumur, Sleman 55281 \\ Email:er_pjr@yahoo.com
}

\begin{abstract}
Silvofishery practices as mangrove utilization have been providing various benefit for local societies, thus it needs to be developed for its product optimization and sustainability. Providing suitable area for silvofisheries is crucial for the development of silvofishery. This study was aimed to classify the mangrove habitat characteristics that were suitable for soka crab farming in the north coast of Rembang Regency, following the success of the north coast of Pemalang Regency. This research were conducted in the north coast of Rembang Regency in 2000, 2003, and 2004 planting years. Perpendicular transects to the coastal line were established on each plantation area. On each transect, three plots of $5 \times 5 \mathrm{~m}$ were established and distributed on each mangrove zone. Mangrove tree density, mud depth, dissolved oxygen, salinity, temperature, $p H$ and plankton density were measured from each plot. The measurements of habitat characteristics were also conducted in the mangrove area of Pemalang, where sok a crab farming was developed earlier as a comparison between areas with the same plantation period). Data collected from all plot were averaged and differentiated based on Mangrove zonation. Data of each zone were treated as relevé. The relevé of the two study sites (Rembang and Pemalang) were then analyzed using cluster analysis with Mean Euclidean Distance (MED). The results showed that the cluster was relatively less various. There were two main separated groups with cluster distance at 10. This grouping was relatively good, indicated by distinctive similarity of habitat within each group. At cluster distance of 5, there were two main groups which were relevé 3,6,8 with releve 2 and the rest as other group. Whereas the cluster distance of 5 in the releve 3,6,8 was grouped with relevé 2, but it was not clearer than above group. Commonly, mangrove habitat in Rembang was less suitable for soka crab farming because only releve 1 was suitable for the habitat of this crab. Further intervention is required for habitat improvement.
\end{abstract}

Keywords: silvofishery, soka crab, mangrove habitat, Rembang, relevé.

\section{INTISARI}

Pemanfaatan mangrove untuk silvofishery mampu mendatangkan keuntungan bagi masyarakat sekitarnya, maka perlu dikembangkan agar hasilnya optimal dan berkelanjutan. Tujuan penelitian ini untuk mendapatkan klasifikasi karakteristik habitat mangrove yang sesuai untuk pengembangan kepiting soka yang selama ini sudah dikembangkan di Pantai Utara Pemalang. Penelitian dilakukan di Pantai Utara Kabupaten Rembang pada tahun tanam 2000, 2003, dan 2004. Masing-masing tahun tanam dibagi menjadi jalur-jalur tegak lurus garis pantai. Setiap jalur diletakkan 3 petak ukur 5 x 5 m sesuai dengan zonasi yang ada pada hutan mangrove, kemudian diukur kerapatan tanaman mangrove, ketebalan lumpur, DO, salinitas, suhu, pH, dan kepadatan plankton. Sebagai pembanding, maka diambil pula data karakteristik habitat di mangrove Pemalang yang sudah digunakan silvofishery kepiting soka. Data pada setiap petak ukur dirata-rata dan dibedakan pada setiap zonasi. Data setiap zonasi dianggap sebagai relevé. Relevé-relevé pada kedua lokasi kemudian dianalisis menggunakan uji pengelompokan atau cluster analysis dengan metode jarak Mean Euclidean Distance (MED). Hasil penelitian menunjukkan bahwa pada umumnya cluster yang terbentuk 
kurang bervariasi. Sepintas terlihat hanya ada 2 kelompok besar yang terpisahkan, yaitu pada jarak cluster 10. Pengelompokan demikian ini cukup bagus karena kemiripan habitat ditunjukkan secara ekstrim oleh dua kelompok besar tersebut. Meskipun pada jarak cluster 5 terdapat kelompokyaitu relevé 3,6,8 dengan relevé 2, namun demikian kurang terlihat jika dibanding dengan jarak di atasnya. Pada umumnya habitat mangrove di Rembang kurang sesuai untuk pemeliharaan kepiting soka, karena hanya relevé 1 yang sesuai. Perlakuan lebih lanjut untuk perbaikan habitat diperlukan agar jenis kepiting ini dapat hidup dengan optimal.

Kata kunci: silvofishery, kepiting soka, habitat mangrove, Rembang, relevé.

\section{PENDAHULUAN}

Fungsi mangrove sangat besar terhadap kehidupan di daratan, di antaranya menahan gelombang pasang, abrasi, dan intrusi air laut (Hogarth, 1999). Pentingnya fungsi ini sering tidak disadari oleh masyarakat sekitar pantai, terbukti dengan cara pemanfaatan mangrove yang kurang memperhatikan aspek konservasi. Pemanfaatan hutan mangrove yang berhubungan langsung dengan perekonomian masyarakat salah satunya adalah hasil tambak payau. Tambak di Pantai Utara Jawa Tengah sebagian besar berada persis di belakang mangrove. Tambak seperti ini disebut sebagai silvofishery, yaitu perpaduan mangrove dan tambak yang mendasarkan pada fungsi mangrove sebagai nursery ground (Poedjirahajoe, 2010b).

Ada beberapa model silvofishery yang sudah dikembangkan saat ini, yaitu komplangan dan empang parit. Pola komplangan menempatkan tambak berupa hamparan yang terletak di belakang mangrove, sedangkan pola empang parit berupa saluran (caren) yang berada di sela-sela hamparan mangrove. Pada pola empang parit, ikan dipelihara di dalam karamba yang ditenggelamkan sebagian ke dalam parit-parit yang telah dibuat. Konstruksi seperti kedua pola tersebut sangat baik dari segi ekonomis maupun ekologis. Secara ekologis tambak mendapatkan pasokan bahan organik yang tinggi dari hutan mangrove, sehingga produksinya lebih tinggi dibanding dengan tambak konvensional. Secara ekonomis, dengan meningkatnya produksi maka meningkat pula nilai ekonominya (Poedjirahajoe, 2009).

Beberapa kawasan yang mempunyai mangrove cukup luas di Pantai Utara Jawa Tengah dan memungkinkan untuk silvofishery selain Pemalang adalah Kendal, Jepara, dan Rembang. Dari ketiga kawasan tersebut, nampaknya mangrove di Rembang lebih siap dikembangkan untuk silvofishery, karena mempunyai kerapatan yang tinggi dan dikelola dengan baik (Poedjirahajoe, 2007). Selain itu masyarakat Rembang sebagian besar adalah nelayan, sehingga jika terjadi gelombang tinggi dan tidak bisa melaut, maka para nelayan dapat diarahkan ke budidaya jenis ikan yang mempunyai nilai ekonomi tinggi. Di Pemalang jenis yang dibudidayakan saat ini adalah kepiting soka. Kepiting soka sebenarnya merupakan jenis kepiting payau biasa (Scylla serrata) yang dibudidayakan menggunakan teknologi moulting, sehingga diperoleh karapak lunak. Teknik moulting tersebut secara ekologis tidak berpengaruh terhadap habitat, akan tetapi justru memberi pengaruh yang besar pada sektor ekonomi masyarakat, karena harganya menjadi 2 kali lipat dibanding kepiting biasa (Poedjirahajoe, 2010a).

Untuk melihat ketepatan lokasi silvofishery di kawasan mangrove Pantai Rembang, maka habitat 
mangrove tersebut perlu diklasifikasi dengan menggabungkan habitat mangrove di Pemalang, agar dapat diketahui habitat mana di mangrove Rembang yang sesuai untuk silvofishery. Pada klas-klas yang sama menunjukkan bahwa lokasi tersebut sesuai atau tidak sesuai untuk silvofishery.

\section{BAHAN DAN METODE}

\section{Lokasi Penelitian}

Lokasi penelitian berada di kawasan mangrove Pantai Utara Rembang (Gambar 1) dan Pemalang (sebagai pembanding). Kedua lokasi ini berada pada satu garis pantai, akan tetapi karena tidak berdampingan dan agak berliku, maka besar kemungkinan faktor habitat tidak sama. Penelitian dilakukan pada bulan Mei-Juni 2014.

\section{Cara Penelitian}

Ditentukan 3 tahun tanam (2000, 2003, dan 2004) pada masing-masing kawasan. Penentuan tahun tanam tersebut disamakan dengan mangrove Pemalang supaya memenuhi syarat untuk klasifikasi. Pada setiap tahun tanam diukur luasnya dan ditentukan jalur-jalur tegak lurus garis pantai. Jalur-jalur tersebut digunakan sebagai ulangan. Pada setiap jalur dibagi menjadi 3 zona yang sama (dari arah laut ke darat) sebagai perlakuan, yaitu zona proksimal (depan), medial (tengah), dan distal (belakang). Perpaduan tahun tanam dan zonasi merupakan suatu relevé (Dombois dan Ellenberg, 1974). Pada setiap zona dibuat petak ukur berukuran 5 x 5 m, dengan 2 kali ulangan. Jika ulangan dirata-rata, maka pada setiap lokasi terdapat $3 \times 3=9$ PU atau 9 relevé, sehingga pada 2 lokasi (Rembang dan Pemalang) terdapat 18 relevé. Pada setiap relevé dilakukan pengukuran terhadap kerapatan tanaman, suhu, $\mathrm{pH}$, salinitas, DO, N, P, K, dan kepadatan plankton.
Kerapatan tanaman mangrove diukur dengan cara menghitung jumlah tanaman dalam setiap PU, sedangkan pengukuran suhu dilakukan dengan cara mencelupkan termometer stik ke dalam air pada batas garis alat, kemudian dibaca suhunya pada display. Salinitas diukur dengan menggunakan salt test yang dicelupkan dalam air sebatas tanda, kemudian angka yang muncul pada display dicatat. DO diukur dengan Oxymeter dengan cara mencelupkan bagian sensor ke dalam air, kemudian dibaca angka yang muncul pada display. Pengambilan contoh plankton di perairan mangrove menggunakan plankton net yang berupa saringan dari 51 air dipadatkan dalam $10 \mathrm{ml}$ (Robinson et al., 1996). Plankton diamati di Laboratorium Ekologi Hutan Fakultas Kehutanan UGM dengan cara mengamati di bawah mikroskop binokuler pada hemacytometer yang telah ditetesi $1 \mathrm{ml}$ air plankton yang dipadatkan. Jumlah total plankton dihitung dengan rumus : $\mathrm{N}=\mathrm{n}_{1} \times 10^{4}$. $\mathrm{N}$ adalah jumlah total plankton, sedangkan $\mathrm{n}_{1}$ adalah jumlah plankton dalam satu petak hemacytometer.

Analisis untuk mengetahui kandungan unsur N, P, dan $\mathrm{K}$ yang terkandung di substrat yaitu dengan menggunakan Atomic Absorbsion Spectrophotometer (AAS). AAS merupakan metode analisis unsur secara kuantitatif yang pengukurannya berdasarkan penyerapan cahaya dengan panjang gelombang tertentu oleh atom logam dalam keadaan bebas (Skoog et al., 2000). Di Indonesia, penggunaan metode ini telah banyak digunakan dalam pelatihanpelatihan dan magang analisis personil laboratorium dari instansi pemerintah pusat maupun daerah, perguruan tinggi, perusahaan swasta, dan praktek lapang pelajar dan mahasiswa, serta kegiatan uji silang hasil analisis antar laboratorium tanah secara nasional (Sulaeman, et al., 2005). 

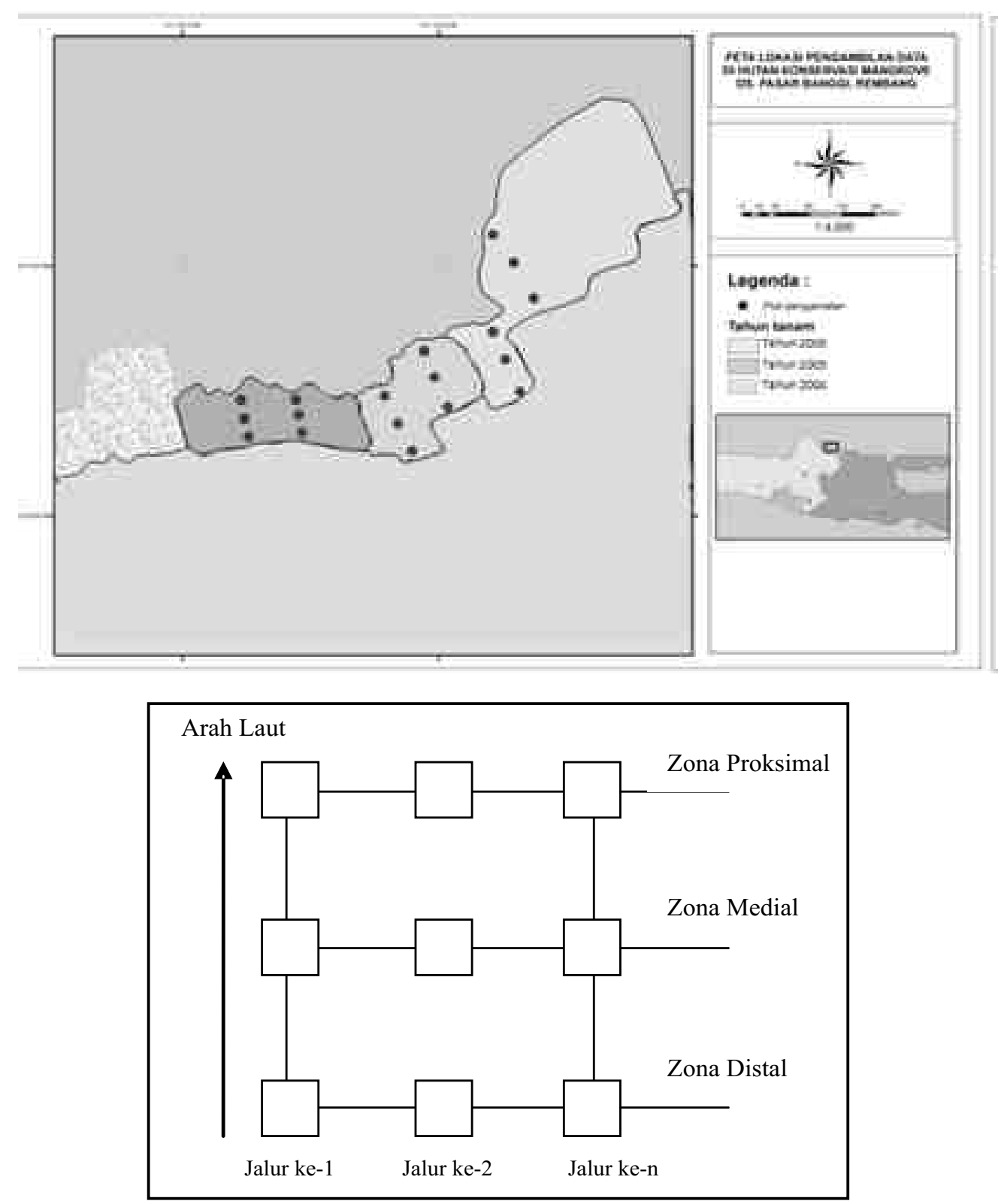

Gambar 1. Peta lokasi pengambilan data di Kabupaten Rembang (atas) dan desain peletakan plot pengamatan (bawah)

\section{Analisis Data}

Data yang terkumpul pada setiap relevé selanjutnya dianalisis untuk melihat klasifikasi dengan menggunakan software Primer 6.1. Analisis tandan (cluster analysis) merupakan cara klasifikasi yang menempatkan suatu ukuran yang sama ke dalam suatu grup-grup atau tandan. Grup-grup tersebut dapat menggambarkan suatu komunitas kawasan (Ludwig dan Reynold, 1988). Koefisien jarak dapat dihitung dengan berbagai formula. Formula yang sering digunakan adalah MED (Mean
Euclidean Distance). Formula ini mendasarkan pada perhitungan jarak rata-rata antar variabel. Bentuk formula sebagai berikut (Ludwig dan Reynold, 1988):

$$
d i j=\sqrt{\frac{\sum_{k=1}(X i k-X j k)^{2}}{m}}
$$

Keterangan :

d ij : koefisien jarak matriks i ke j

$\mathrm{X}$ ik : Variabel ke k diukur pada obyek i

$\mathrm{X} \mathrm{jk} \quad$ : Variabel ke $\mathrm{k}$ diukur pada obyek $\mathrm{j}$ 
m : Total variabel

Hasil analisis tandan merupakan dendrogram yang menggambarkan klasifikasi (pengelompokan) dan stratifikasi pada unit-unit ekologis berdasarkan parameter tanaman untuk setiap koefisien jarak tandan. Dengan demikian, pada koefisien jarak tandan yang berbeda maka terjadi perbedaan dalam pengelompokan unit-unit ekologisnya. Demikian seterusnya sampai pada jarak tertinggi. Jarak tandan terendah menunjukkan kedekatan hubungan antara unit-unit ekologis, yang berarti mempunyai nilai kesamaan yang tinggi. Biasanya ditunjukkan dengan banyaknya jumlah unit ekologis yang mengelompok.

\section{HASIL DAN PEMBAHASAN}

Penelitian terhadap karakteristik habitat mangrove dilakukan dengan cara mengamati dan mengukur oksigen terlarut (DO), $\mathrm{pH}$, suhu, kepadatan plankton, $\mathrm{N}$ total, $\mathrm{P}$ tersedia, $\mathrm{K}$ tersedia, dan kerapatan tanaman. Hasil penelitian disusun pada Tabel 1.

Hasil penelitian menunjukkan bahwa lokasi Rembang tahun tanam 2000 pada zona proksimal (RBG1_A), RBG3_A, dan RBG3_B mempunyai nilai DO terendah dibanding lokasi lainnya. Sementara kepadatan plankton di RBG1_A dan PML2_C menunjukkan angka yang paling rendah. Kandungan N pada umumnya di lokasi Rembang lebih rendah dari Pemalang. Tabel 1 menunjukkan

Tabel 1. Hasil Analisis Karakteristik Habitat Mangrove di Rembang dan Pemalang

\begin{tabular}{rrrrrrrrrrr}
\hline & & \multicolumn{10}{c}{ Parameter } \\
\cline { 3 - 10 } No. & Relevé & $\begin{array}{c}\text { DO } \\
(\mathrm{ppm})\end{array}$ & pH & $\begin{array}{c}\text { Suhu } \\
\left({ }^{\circ} \mathrm{C}\right)\end{array}$ & $\begin{array}{c}\text { Salinitas } \\
(\%)\end{array}$ & $\begin{array}{c}\text { Kepadatan } \\
\text { Plankton/1 }\end{array}$ & $\begin{array}{c}\text { Ntot } \\
(\%)\end{array}$ & $\begin{array}{c}\text { Ptsd } \\
(\mathrm{ppm})\end{array}$ & $\begin{array}{c}\text { Ktsd } \\
(\mathrm{ppm})\end{array}$ & n/ha \\
\hline 1 & RBG1_A & 9,65 & 7,88 & 27,22 & 31,33 & $180.000,00$ & 0,11 & 18 & 122 & 3200 \\
2 & RBG1_B & 11,00 & 6,55 & 27,11 & 32,33 & $743.333,33$ & 0,05 & 13 & 85 & 2600 \\
3 & RBG1_C & 10,13 & 6,77 & 27,00 & 31,66 & $636.666,66$ & 0,02 & 7 & 39 & 2800 \\
4 & RBG2_A & 12,00 & 6,88 & 27,88 & 35,00 & $406.666,66$ & 0,09 & 13 & 136 & 2200 \\
5 & RBG2_B & 11,93 & 6,88 & 27,44 & 32,33 & $376.666,66$ & 0,02 & 8 & 38 & 2400 \\
6 & RBG2_C & 10,96 & 7,00 & 28,00 & 33,33 & $506.666,66$ & 0,05 & 9 & 84 & 2200 \\
7 & RBG3_A & 9,60 & 6,55 & 27,11 & 33,33 & $376.666,66$ & 0,08 & 11 & 95 & 1200 \\
8 & RBG3_B & 9,46 & 7,00 & 27,55 & 33,00 & $570.000,00$ & 0,09 & 16 & 127 & 2100 \\
9 & RBG3_C & 11,92 & 8,00 & 29,00 & 34,00 & $380.000,00$ & 0,07 & 11 & 101 & 2200 \\
10 & PML1_A & 10,71 & 7,00 & 31,33 & 21,76 & $280.000,00$ & 0,17 & 39 & 182 & 1800 \\
11 & PML1_B & 10,62 & 7,33 & 32,00 & 28,46 & $360.000,00$ & 0,14 & 40 & 191 & 3200 \\
12 & PML1_C & 11,05 & 7,33 & 31,66 & 22,56 & $206.666,66$ & 0,13 & 32 & 175 & 1200 \\
13 & PML2_A & 11,41 & 7,33 & 33,33 & 29,46 & $243.333,33$ & 0,11 & 33 & 173 & 3467 \\
14 & PML2_B & 10,66 & 7,66 & 33,00 & 29,46 & $246.666,66$ & 0,17 & 29 & 198 & 2560 \\
15 & PML2_C & 10,32 & 7,00 & 33,33 & 27,53 & $166.666,66$ & 0,14 & 55 & 190 & 2200 \\
16 & PML3_A & 10,87 & 7,00 & 33,33 & 28,13 & $233.333,33$ & 0,11 & 34 & 178 & 1240 \\
17 & PML3_B & 12,03 & 7,00 & 33,33 & 28,16 & $220.000,00$ & 0,09 & 41 & 171 & 1100 \\
18 & PML3_C & 10,49 & 7,00 & 33,33 & 28,30 & $290.000,00$ & 0,10 & 37 & 165 & 2400 \\
\hline
\end{tabular}

Keterangan :

1 : Tahun tanam 2000

2 : Tahun tanam 2003

3 : Tahun tanam 2004
A : Zona Proksimal

B : Zona Medial

C : Zona Distal
RGB : Lokasi Rembang

PML : Lokasi Pemalang

$\mathrm{n} / \mathrm{ha}$ : Kerapatan mangrove 
bahwa pada umumnya rata-rata kandungan DO dari 2 lokasi adalah sama, yaitu antara 9,46-12,03 ppm. Rendahnya DO di beberapa lokasi di Rembang (relevé 1, 7, dan 8) kemungkinan disebabkan oleh aktivitas fotosintesis fitoplankton yang masih belum maksimal (Nontji, 2008). Keadaan ini bisa terjadi karena kekeruhan yang tinggi atau cuaca yang mendung sehingga aktivitas fotosintesis terganggu. Untuk pH lokasi Rembang agak sedikit lebih kecil dibanding Pemalang, namun demikian masih dalam batas normal. Silvofishery di Pemalang sudah ada sejak tahun 2000. Penelitian Poedjirahajoe (2008) menyimpulkan bahwa tahun tanam yang terbaik untuk silvofishery (mendasarkan pada berat panen kepiting soka) adalah tahun tanam 2004 (selisih berat rata-rata $95 \mathrm{~kg}$ ), kemudian tahun tanam 2003 (selisih berat rata-rata $75 \mathrm{~kg}$ ), dan yang kurang adalah tahun tanam 2000 (selisih berat rata-rata $45 \mathrm{~kg}$ ). Dari urutan tahun tanam dapat dilihat bahwa semakin meningkat tahun tanam, berat kepiting soka semakin menurun. Meskipun demikian pola silvofishery tetap menghasilkan peningkatan berat kepiting soka dibanding dengan tambak konvensional.

Suhu biasanya berkorelasi dengan plankton (Nybakken, 1988). Peningkatan suhu akan berpengaruh pada menurunnya kepadatan plankton. Tabel 1 menunjukkan bahwa rata-rata suhu di Pantai Rembang pada umumnya lebih rendah dibanding Pemalang. Ada beberapa hal penyebab tingginya suhu, antara lain akibat terkena sinar matahari secara langsung jika kawasan mangrove agak terbuka karena jarak antar pohon agak lebar. Secara teori intensitas matahari secara langsung justru membuat proses fotosintesis oleh fitoplankton menjadi maksimal, akan tetapi dapat pula membuat biota lain menjadi letal atau mengurangi aktivitasnya (termasuk decomposer), sehingga dapat menurunkan kepadatan plankton (Hogarth, 1999). Kedua, tingginya suhu dapat disebabkan oleh proses metabolisme dalam perairan yang meningkat sehingga $\mathrm{CO}_{2}$ lebih tinggi dibanding $\mathrm{O}_{2}$. Kondisi ini didapati apabila peran bakteri an-aerob sangat tinggi akibat perairan terkena limbah logam berat atau bahan organik lainnya (Ricklefs dan Latham, 1993).

Salinitas merupakan faktor abiotik perairan yang berperan tinggi dalam metabolisme biota air. Tubuh biota termasuk kepiting soka akan sulit menerima kadar salinitas yang tinggi akibat lisis (Koch, 2001). Tabel 1 menunjukkan bahwa salinitas mangrove di Pemalang masih berada pada kisaran payau (21-19 \%), sedangkan di Rembang salinitasnya cenderung lebih tinggi, hampir mendekati salinitas air laut. Namun demikian, beberapa lokasi/habitat di Rembang ada yang mempunyai kemiripan dengan Pemalang, misalnya relevé 1 dengan relevé 15 , relevé 4, 5, 7, dan 9 dengan relevé 11 (Gambar 2). Keadaan ini bisa terjadi karena pengaruh habitat pada umumnya tidak hanya oleh satu faktor saja, tetapi faktor yang secara bersama-sama sehingga tingginya salinitas dapat diatasi pengaruhnya secara individual dengan suhu, $\mathrm{pH}$ ataupun DO (Dombois dan Ellenberg, 1974).

Hasil penelitian pada Tabel 1 diatas juga menunjukkan bahwa kepadatan plankton pada umumnya dipengaruhi oleh beberapa hal, antara lain oleh suhu dan salinitas. Namun demikian, keberadaan plankton sangat bergantung pada intensitas cahaya matahari ke perairan. Umumnya perkembangan plankton berasal dari proses fotosintesis sehingga tanpa aktivitas ini, maka populasi akan menurun (Nybakken, 1988). Sementara hasil penelitian tentang keharaan didapatkan bahwa lokasi Rembang mempunyai kandungan $\mathrm{N}$ yang rendah dibanding Pemalang. Unsur hara N, P, K berperan penting dalam pertumbuhan tanaman. Tabel 1 menunjukkan bahwa rata-rata unsur $\mathrm{N}, \mathrm{P}, \mathrm{K}$ tertinggi 

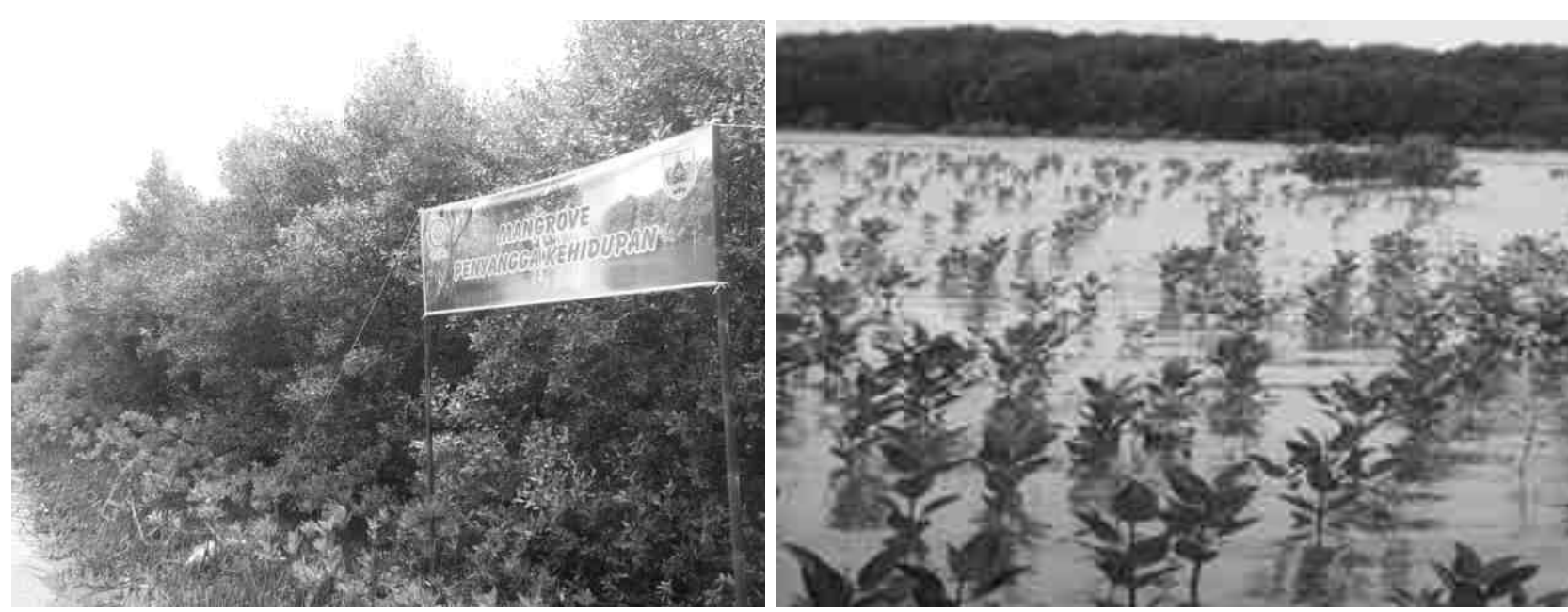

Gambar 2. Kondisi vegetasi pada mangrove di Kabupaten Pemalang/relevé 11 (kiri) dan di Kabupaten Rembang / relevé 1 (kanan)

ada di lokasi Pemalang. Keharaan merupakan bagian penting dari ekosistem. Di Indonesia keharaan mangrove jarang sekali diteliti, sehingga informasi penting tentang penggunaan dan simpanan hara masih belum terungkap (Poedjirahajoe, 2008). Meskipun lumpur mangrove labil dan penyerapan hara oleh akar sangat sulit, namun ketersediaan hara di permukaan sangat menentukan besarnya pada waktu terjadi endapan sedimen. Dengan demikian, keberadaan hara dalam substrat mangrove pada akhirnya tergantung oleh pasokan hara dari sungai maupun laut sesuai dengan sifat siklus hara yang ada di perairan, yaitu siklus hara terbuka. Di hutan mangrove keperluan tanaman terhadap hara sebagian besar $(90 \%)$ disediakan oleh aktivitas decomposer melalui proses perombakan bahan organik menjadi anorganik (dekomposisi). Hara yang berasal dari sungai maupun laut hanya terserap akar sekitar 5-10\% saja, karena lumpur yang labil (Kathiseran dan Bingham, 2001).

Gambar 3 menunjukkan bahwa pada umumnya cluster yang terbentuk kurang bervariasi. Sepintas terlihat hanya ada 2 kelompok besar yang terpisahkan, yaitu pada jarak cluster 10. Hasil penelitian Poedjirahajoe (2007) di Pantai Pemalang, menunjukkan bahwa karakteristik habitat mangrove untuk kepiting soka terbaik pada relevé nomer urut 5 sampai 11. Selanjutnya dijelaskan pada penelitian tersebut bahwa sejak tahun 2000 Pantai Utara Pemalang telah mengembangkan silvofishery empang parit di lahan mangrove. Keberhasilan silvofishery ditunjukkan dengan meningkatnya berat panenan. Kemudian pada tahun 2002, silvofishery dikembangkan dengan komoditas kepiting soka. Kenaikan berat panen disebabkan karena habitatnya sesuai dengan kondisi kepiting untuk berkembang biak. Faktor utama yang berpengaruh adalah salinitas dan suhu. Kepiting soka pada perkembangannya membutuhkan salinitas payau, meskipun pada fase juvenil memerlukan salinitas yang tinggi karena masa perkembangbiakan biasanya berada di tengah laut dengan salinitas yang tinggi. Demikian pula dengan suhu. Suhu optimal perairan yang dibutuhkan oleh kepiting soka adalah sekitar $25-27^{\circ} \mathrm{C}$. Aktivitas metabolisme tidak akan maksimal pada suhu diatas $27^{\circ} \mathrm{C}$. Sekali lagi ditekankan disini bahwa suhu tidak hanya berasal dari intensitas cahaya matahari saja, tetapi juga terkait dengan keberadaan oksigen terlarut dan aktivitas planktonik (Nontji, 2008).

Teknik pemeliharaan yang mudah dan waktu pembesaran yang singkat (20-30 hari) menyebabkan masyarakat petambak Pemalang tetap mempertahan- 


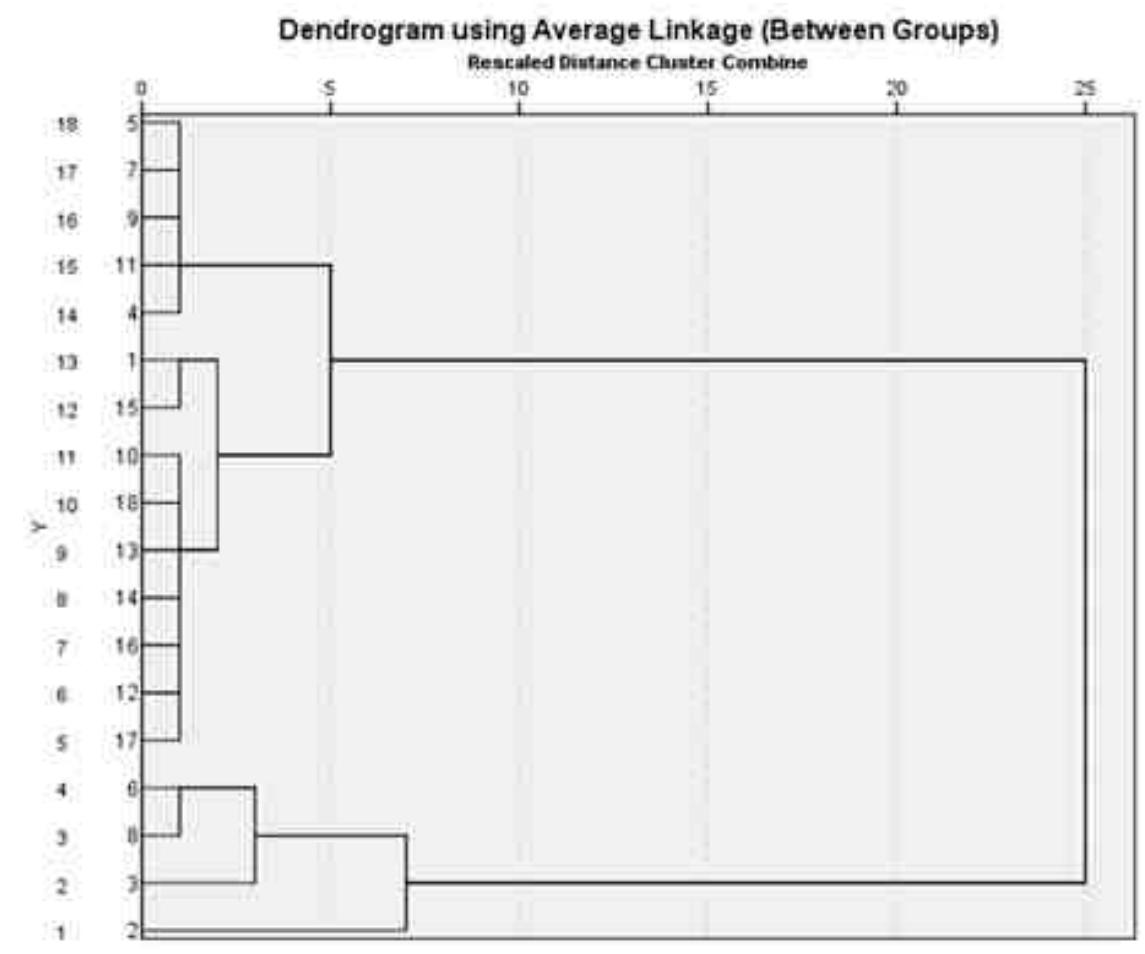

Gambar 3. Dendrogram Pengelompokan Habitat Mangrove di Rembang dan Pemalang

kan budidaya kepiting ini sampai sekarang. Pelestarian hasil salah satunya dilakukan dengan tetap memelihara habitat yang sesuai untuk kehidupan kepiting tersebut. Penanaman mangrove terus ditingkatkan, karena keyakinan mereka akan penambahan kepadatan plankton sebagai suplai makanan secara alami dari perairan.

Habitat terbaik di Pemalang ternyata ada yang mirip dengan habitat di Pantai Utara Rembang, yaitu relevé 1 (Gambar 2). Hasil ini menunjukkan bahwa pada umumnya habitat di Rembang tidak sesuai untuk pemeliharaan kepiting soka. Dengan demikian, dapat dijelaskan bahwa hanya relevé 1 yang dapat dijadikan lokasi pengembangan silvofishery kepiting soka. Namun demikian hasil diatas bukanlah hasil yang baku. Tindakan konservasi ekosistem perlu dilakukan agar lokasi yang belum sesuai bisa menjadi sesuai, yaitu dengan cara menghadirkan faktor-faktor/karakteristik habitat yang dianggap belum sesuai untuk disesuaikan dengan yang ada di
Pemalang (Poedjirahajoe, 2007). Dengan hasil penelitian ini, maka dapat disarankan kepada Pemerintah Daerah Kabupaten Rembang bahwa untuk pengembangan silvofishery ke depan hendaknya tidak menggunakan jenis kepiting soka.

\section{KESIMPULAN}

Dari hasil penelitian dan pembahasan dapat disimpulkan unit-unit ekologis yang membentuk klas-klas dari habitat mangrove di Rembang secara umum tidak menunjukkan kemiripan dengan habitat silvofishery di Pemalang. Dari hasil penelitian di atas dapat disarankan bahwa tindakan konservasi ekosistem yang perlu dilakukan agar habitat di Rembang sesuai dengan Pemalang adalah menghadirkan faktor-faktor/karakteristik habitat yang dianggap belum sesuai untuk disesuaikan dengan kondisi habitat yang ada di Pemalang, antara lain DO, salinitas, dan kepadatan plankton, sebagai 
contoh dengan penambahan penanaman yang lebih rapat.

\section{DAFTAR PUSTAKA}

Hogarth P. 1999. The Biology of Mangrove. Mc Graw-Hill Pub. 112.

Kathiseran K \& Bingham BL. 2001. Biology of mangroves and mangrove ecosystems. Advances in Marine Biology 40, 81-251.

Koch EW. 2001. Beyond light: Physical, biological, and geochemical parameters as possible submersed aquatic vegetation habitat requirements. Estuaries 24, 1-17.

Ludwig JA \& Reynold JF. 1988. Statistical Ecology. Mc-Graw Hill. London. 184.

Mueller-Dombois D \& Ellenberg H. 1974. Aims and Methods of Vegetation Ecology. John Willey and Sons. New York.

Nybakken JW. 1988. Ocean Biology: An Ecological Approach. John Wiley \& Sons.

Nontji A. 2008. Plankton Laut. Penerbit LIPI. Jakarta. 331.

Poedjirahajoe E. 2007. Pengelompokan mangrove berdasarkan faktor habitat di Pantai Utara Jawa Tengah. Prosiding Seminar Hasil-Hasil Penelitian Bidang Perikanan dan Kelautan. Fakultas Pertanian UGM, 2007.

Poedjirahajoe E. 2008. Kisaran efektif oksigen terlarut untuk pengembangan silvofishery di Kawasan Rehabilitasi Mangrove Pantai Utara Rembang. Prosiding Seminar Hasil-Hasil Penelitian Bidang Perikanan dan Kelautan. Fakultas Pertanian UGM, 2008.

Poedjirahajoe E. 2009. Peranan Mangrove dalam Peningkatan Berat Kepiting Soka di Pantai Utara Pemalang. DPP Fakultas Kehutanan UGM.

Poedjirahajoe E. 2010. Peranan ekosistem mangrove dalam pengembangan silvofishery. Prosiding Seminar Hasil-Hasil Penelitian Bidang Perikanan dan Kelautan. Fakultas Pertanian UGM, 2010.

Poedjirahajoe E, Sidharta BR, Probosunu N. Ambarwati D, \& Utami D. 2010. Analisis ekologis dan variasi genetik mangrove di pesisir Kabupaten Sumbawa Barat dan Kabupaten Lombok Timur. Prosiding Seminar PERHAPI TPT XX Lombok-NTB.
Ricklefs RE \& Latham RE. 1993. Global patterns of diversity in mangrove floras. Dalam : Species Diversity in Ecological Communities. Ricklefs RE \& Schulter D (Eds.). University of Chicago Press, Chicago, 215-229.

Robinson CLK, Hay DE, Booth J, \& Truscott J. 1996. Standard methods for sampling resources and habitats in coastal subtidal regions of British Columbia: Part 2-Review of sampling with preliminary recommendations. Canadian Technical Report of Fisheries and Aquatic Sciences. XXXX: xii +119.

Skoog DA, West DM, Holler JF, \& Crouch SR. 2000. Fundamentals of Analytical Chemistry. Brooks Cole. USA.

Sulaeman, Suparto, \& Eviati. 2005. Analisis Kimia Tanah, Tanaman, Air, dan Pupuk. Balai Penelitian Tanah, Badan Penelitian dan Pengembangan Pertanian, Departemen Pertanian. Bogor. 